\title{
Evaluation of Effect of Eddy Currents in PLC Influenced by Atmospheric Corrosion in the Electronics Industry
}

\author{
Gustavo López Badilla ${ }^{1}$, Elizabeth Romero Samaniego ${ }^{2}$, Sandra Luz Toledo Perea ${ }^{2}$, Miriam Maleny García \\ Castrellon $^{3}$ and Luis Alberto Gameros Rios ${ }^{3}$ \\ 1. Researcher-Academic, Technological Institute of Mexicali (TIM), Mexicali, Baja California, México \\ 2. Researcher-Academic, Technological Institute of Ensenada (TIE), Ensenada, Baja California, México \\ 3. Students of Electronic Engineering, Technological Institute of Mexicali (TIM), Mexicali, B.C., México
}

Received: March 22, 2013 / Accepted: April 15, 2013 / Published: May 25, 2013.

\begin{abstract}
Inductive proximity sensors contain an internal coil. When a current flow through it, a magnetic field is generated, which has the direction of the electric currents involved in it, as electrical flow in the input or output area. The coil or winding of the inductive sensor induces Foucault currents in the material to be detected, that are originated by eddy currents. These electrical flows generate a magnetic field, which opposes to the sensor coil, causing a reduction in the inductance of micro inductors of electronic devices. This reduction of the internal inductance originates bad function in the micro inductors used in the programming logic controller (PLC). This PLC is in the manufacturing processes of the electronics industry and reduces their operation yielding. Sometimes the actuators of these electronic systems not operate correctly, and causing stops in the activities of industrial equipments and machines, being a factor of economic losses. A study of micro evaluation of these inductors which are elements of the relays of PLC was made to determine the influence of corrosion in these components. The analysis showed micro corrosion in these devices with images obtained of the scanning electron microscopy (SEM) and also was made a correlation of the climatic factors as relative humidity $(\mathrm{RH})$ and temperature with the corrosion rate (CR). The evaluation was made in indoor of an industrial plant which fabricate microelectronic components in Mexicali city. The major factors, which cause an adverse effect in the operation of PLC of this industrial plant was the humidity and sulfurs, which originates the deterioration of components of PLC. The study was made from 2010 to 2011.
\end{abstract}

Key words: Foucault currents, PLC, micro corrosion, electronics industry.

\section{Introduction}

In the electromagnetic process, the induced current is forced to follow well defined paths through wires made of conductive material. The electrical equipment are formed by parts, pieces of conductor moving in a magnetic field or are located in a variable magnetic field, leading to circulating currents induced by the conductor volume. These are called eddy currents or Foucault currents. When placing a piece of metal in a magnetic field varying with time $B(t)$, generates an electric field that produces a motion of free charges in

Corresponding author: Gustavo López Badilla, Dr., research fields: environment, corrosion, materials and surface analysis. E-mail: glopezbadilla@yahoo.com. the metal conductor, causing an electromagnetic field as is mentioned in the next mathematical equation:

$$
\oint E \cdot d l=-\frac{d}{d t} \int_{\mathrm{S}} B \cdot \mathrm{dS}
$$

This Foucault current generates variations in the electromagnetic systems used in the electronics industry [1].

\subsection{Foucault Currents}

The eddy currents occur when an electrical conductor passes through a variable magnetic field, or vice versa. The relative movement causes an electron flow or current induced within the electrical conductor. These circular currents create electromagnetic fields 
with opposing magnetic fields to the effect of applied magnetic field. If the magnetic field applied is very strong, or the electrical conductivity of electrical conductor is higher, with a high speed or relative motion; the parasite currents and fields will be very high as an opposition of normal electrical current [2]. The cores of coils and transformers are generated induced voltages, due to variations magnetic flux those that are in the cores. These induced voltages are caused by eddy currents, occurring in the core, which are called Foucault currents, and are not optimal for good electrical efficiency of electromagnetic devices. Eddy currents create energy losses through the Joule effect. More specifically, these currents transform electrical energy, as kinetics in unwanted heat, being a negative effect in the electromagnetic of electronic systems. It, decreases the efficiency of many devices using magnetic fields variables such as core transformers iron and electric motors used in the electronics industry. These electrical currents losses are minimized using cores with low magnetic conductivity (such as ferrite) or thin magnetic material sheets, known as laminates. Electrons cannot cross the insulating layer between the laminate and, therefore, no can open circular arcs. Charges accumulate at the ends of the laminate, in a process analogous generate the Hall Effect, producing electric fields that precluding further accumulation of charges and eliminating the eddy currents. If the distance is very short between adjacent laminated, (for example while the number of laminates per unit area are higher, and perpendicular to the applied field), it will remove higher currents Foucault, and therefore less heating of core [3].

\subsection{Electromagnetic Induction}

A variation of the magnetic flux induces current metal parts, and these currents are called parasites currents. If have an iron and a rotating metal disc around an axis, and a part of the disc passes inside to the magnetic field created by the magnet, will occur a variation of magnetic flux which induces a current in the object as a variation and represented by Lenz's law [4]. The eddy currents produce two effects: one side is a magnetic brake disc and other heating by Joule effect, which can be inconvenient. This can be reduced to avoid the possible paths inside the metal parts. For example, in the transformers are laminated iron cores minimizing these electrical current losses in the electromagnetic systems and reducing the presence of eddy currents. If compare the function of electromagnetic system with the pendulum operation, the materials are similar, which are constituted by copper plate. Between the poles of an electromagnet is observed to be slowing up completely stopped, this effect occurring rapidly the higher the intensity of field. Being a copper plate material magnetic braking of the pendulum is not due to attraction of the magnet poles. In the plate, when is cutting the flow between the pole pieces, an electromotriz force (EMF) are induced according to Lenz's law. As copper is a good conductor and the plate offers a great the passage section of the flow, its ohmic resistance is small and intense, being induced currents [5]. These currents are opposed to the action of the source produces, and the self-oscillation of the pendulum, thus acting as a brake. These systems operate as similar activities.

\subsection{PLC}

A programmable logic controller (PLC) is a computer used in automatic engineering or industrial automation to automate electromechanical and electromagnetic processes, such as control of machinery on factory assembly lines of manufacturing areas. PLC is used in many industries and machines. These PLC are designed for multiple input and output to control variables as temperature ranges, immunity to electrical noise, and resistance to vibration and impact and other characteristics presented $\mathrm{n}$ the electronics industry [6]. Programs to control machine operation are typically stored in battery backed or non-volatile memories. A PLC is an example of a hard real-time system where the output results must be 
produced in response to input conditions within a limited time; otherwise it will not produce the desire results. In recent years, small products called programmable logic relays (PLRs), have become more common and accepted to be used in industrial plants with electronic devices and systems. These are very similar to the PLC, and are used in some activities being one of them, the light industry, where exists few signals coming from the real world and some emerging, that are involved at low cost. These small devices are typically made in a common physical size and shape by several manufacturers, and branded the largest manufacturers of PLC to complete their lower end product range. Most of them are between 8 and 12 digital inputs, 4 and 8 discrete outputs, with 2 analog inputs. The size is usually about $10 \mathrm{~cm}$ wide and $7.5 \mathrm{~cm}$ high and $7.5 \mathrm{~cm}$ deep. Most of these devices include a small LCD screen for viewing simplified ladder logic, only a very small portion of the program is visible at any given time and the status with open and close operations. Normally these screens are accompanied by a four way rocker keypad plus four more separate push buttons, and are used to navigate and edit the logic. Most have a small plug for connecting via RS-232 or RS-485 to a personal computer so that programmers can use simple Windows applications for programming instead of being forced to use the LCD screen and the set of small switches for this purpose. PLC are usually modular and greatly expandable, the PLR are usually not modular or expandable, but their price can be two orders of magnitude less than a PLC and they still offer robust design and deterministic execution logic [4].

\subsection{Corrosion in Electromagnetic Devices (EMD)}

The majority of industries are characterized by the implementation of manufacturing processes with electronic devices and systems, to control, storage and measure some variables in these industrial processes. The production areas have electrical, electromechanical, electromagnetic and electronic components. These types of macro and micro devices are exposed to aggressive environments in indoor industrial plants in specially in the electronics industry. These harsh atmospheres have corrosive gases and particles and affecting to these facilities. In specially, the use of electronic devices and boards, with components sensitive to the presence of corrosion, are damaged very easy and fast [7]. It decrease the production yielding of technological systems, and is exposed to significant risks, especially when it comes, the operation of electric circuits or printed boards, that can be attacked by various acid gases found in the atmosphere. Additionally, this problem may go largely unnoticed for the operator, only becoming visible when an error or an unexpected shutdown of a production process. One of the air pollutants in Mexicali city which was made this study, is the hydrogen sulfide, which generates sulfurs with the combination of oxygen of the atmosphere. Electromagnetic devices as relays, which are used in electronic devices as PLC, suffer of the corrosion phenomena, and in sometimes not function very well or as an inoperative component. This concern to specialized people of the electronics industry, where utilized a lot quantity of PLC to control various operations in the manufacturing processes. The presence of corrosion affects directly to PLC of industrial plants, damaging their external electrical connections and connectors, in some times only generating corrosion products and in other times, brakes the metallic contacts of copper. Also deteriorate the internal connectors electrical, which are covered by corrosion products and operate inadequately.

The electromagnetic devices (EMD) are very important systems in the electronics industry [8].

\subsection{Electronics Industry in Mexico}

The electronics industry is an important key to the industrial development of our country, with favorable evolution in the past decade and a market-oriented 
industry transitioned to a competitive industry where it is used mainly for the export market. The most important export products are of high technology with a lot of products, being the principal the televisions, cell phones, computer equipments and decoders, as well as some electro-medical equipment and electronic components with integrated circuits of photosensitive semiconductor devices, switches, control panels, transistors and some capacitors [2]. The electronics industry is very important in the manufacturing industry in Mexico, which is measured through economic indicators such as employment, exports and foreign direct investment. This is clearly an industry dominated by multinational companies have established subsidiaries in Mexico for more than five decades. Five sectors up to the electronics industry: electronics consumer, personal computers, telecommunications equipment, electronic components and industrial and medical equipment. In the second half of the nineties, the electronics industry in Mexico was strongly benefited from the signing of the Free Trade Agreement (NAFTA): the value added grew at an average annual rate of $16.4 \%$ between 1994 and 2000. Direct industry grew occupied by 192,000 employees in 1994 to 384,000 in 2000. The period between 2001 and 2003 was outright contraction due to lower global demand and strong competition from other countries, mostly in Asia, among other factors. Figures for 2004 show a significant industry recovery, but still below the levels reached in 2000 [6].

In 2004, the electronics industry in Mexico accounted for $0.9 \%$ of the national value added and $4.8 \%$ of the manufacturing, and 298,000 workers employed directly. Total exports of the industry in the same year were 42.908 million dollars and for the first time in 10 years presented a deficit in the balance of trade: imports totaled 45.697 million dollars. For its hand, foreign investment totaled \$ 696 million in 2004. The main sectors of the electronics industry in Mexico are consumer electronics, computers personal and telecommunications equipment, industrial and medical equipment but have been growing at rates higher than the industry average. More than $75.0 \%$ of the companies are located in states northern border of the country, mainly in Sonora, Baja California and Chihuahua. Jalisco is the state of inside the country with the largest number of companies in the electronics industry [8].

\section{Methodology}

Corrosion appeared in the microelectronic devices evaluated in the electronics industry of Mexicali, generating the Foucault currents which have an adverse effect in the electromagnetic systems. For this analysis was evaluating the production yielding of some PLC used in indoor of industrial plants of this city [9]. Also were analyzed climatic factors and air pollution levels to determine the effect in the corrosion rate (CR) of metallic surfaces of PLC. Evaluation was made of internal and external electrical connectors and connections of PLC during the period evaluated and show the corrosion types in summer and winter seasons.

\subsection{Materials and Methods}

The first process was the evaluation of the operation of relays in winter and summer as electromagnetic devices to analyze the phenomena as a differential transformer with the primary and secondary windings, to detect Foucault currents.

The evaluation of corrosion products to determine the chemical agents that react with the metallic surfaces of copper of electrical connectors of PLC, and know the type of corrosion in each seasons evaluated: summer and winter. The materials used were the electrical connections of PLC deteriorate [10, 11], to correlate with the CR with the concentration levels of hydrogen sulfides $\left(\mathrm{H}_{2} \mathrm{~S}\right)$, sulfur oxides $\left(\mathrm{SO}_{\mathrm{X}}\right)$, nitrogen oxides $\left(\mathrm{NO}_{\mathrm{X}}\right)$, ozone $\left(\mathrm{O}_{3}\right)$ and carbon monoxide (CO), obtained of the Environmental Monitoring Systems (EMS) with the air quality standards (AQS). 


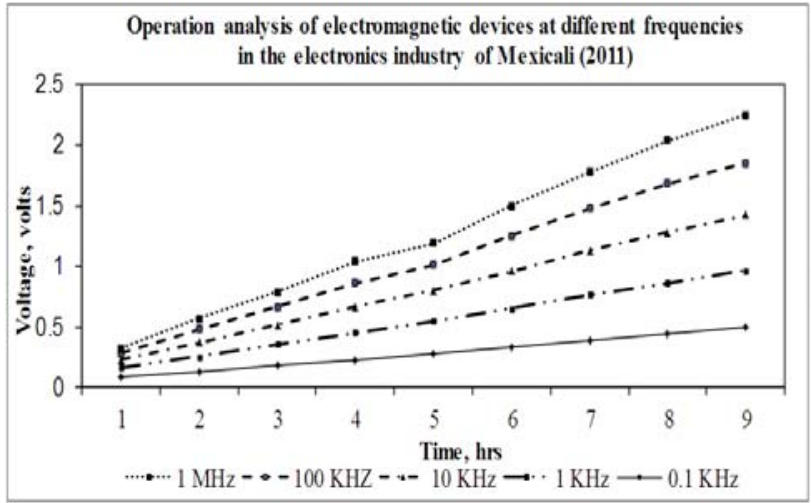

Fig. 1 Evaluation of operation of relays of PLC in an electronics industry in Mexicali (2011).

This information have relevance to the electronics industry, because this chemical agents as particle or gasses, penetrate to indoor of this type of industrial plants. To correlate the information of $\mathrm{CR}$ and the concentration levels in indoor of the electronics industry, was measure sulfurs with the technique of sulfatation plate (TSP) [12].

\subsection{Atmospheric Corrosion}

Atmospheric corrosion (AC) in indoor of the electronics industry is commonly generated by the aggressive environments formed for the presence of sulfurs that in the Mexicali city in winter principally overpass the AQS and damage the metallic surfaces of electrical connectors and connections of the PLC. This originates low capacity in the production processes and in sometimes is necessary stop the manufacturing lines in the industrial areas to repair the PLC or to replace these electronic devices with electromagnetic systems as relays [5].

\subsection{Surface Analysis}

Corrosion products and type of corrosion forms are evaluated by the SEM technique at different scales, obtained the best illustrations to compare at $500 \times$ as the higher view in a microphotography and at $5 \times$ the small view to know at very small scale the corrosion process. These microphotographs showed the deterioration of the metallic copper surfaces in each season evaluated [3].

\section{Results}

The presence of corrosion in electromagnetic devices of PLC is a concerned aspect to managers and owners, which works with the specialized people to reduce or avoid it. This generates a great economic losses by the Foucault currents appeared that decrease the productive yielding of the electromagnetic components and originates expensive costs by the generation of heat in these type of devices used in the electronics systems.

\subsection{Effect of Foucault Currents in Operation of EMD}

Foucault currents originate the loss of electrical current of the electromagnetic devices, and depending of the frequency of operation, is the magnitude of this current loosed. In this study, an analysis of a relays as a mean, used in the PLC by $9 \mathrm{~h}$ a day, in every day of the week, in three months, showed the different operation of this electronic devices at $0.1 \mathrm{KHz}, 1 \mathrm{KHz}$, $10 \mathrm{KHz}, 100 \mathrm{KHz}$ and $1 \mathrm{MHz}$ (Fig. 1).

As showed the last figure, the output voltage at different frequencies are represented the volts that loss the electromagnetic devices indicated in the evaluation process. At $0.1 \mathrm{KHz}$, the lowest voltage loosed was around $0.01 \mathrm{~V}$ and the highest was $0.02 \mathrm{~V}$. In the 1 $\mathrm{KHz}$, was showed a maximum voltage loosed of 0.025 $\mathrm{V}$ with a minimum was $0.3 \mathrm{~V}$. At $10 \mathrm{kHz}$, the smallest value was $0.035 \mathrm{~V}$ and the biggest the $0.045 \mathrm{~V}$ and in the $100 \mathrm{KHz}$ the highest magnitude was $0.09 \mathrm{~V}$ and the smallest was $0.04 \mathrm{~V}$. At $1 \mathrm{MHz}$ the maximum value of loosed voltage was $0.12 \mathrm{~V}$ and the minimum was $0.06 \mathrm{~V}$. This meaning, that at high frequency values are loosed more quantity of volts, and at this magnitude of frequency operate the electromagnetic devices of PLC by the reduced times to function.

\subsection{Correlation of CR, Climatic Factors and Air Pollution}

All figures represents the relation between the CR of cooper and the climatic factors evaluated in this study, as are $\mathrm{RH}$ and temperature, associated to the 
principal air pollutants mentioned above. The chemical agent who promotes the corrosion process with major negative effect in copper and silver probes was the $\mathrm{H}_{2} \mathrm{~S}$ in the first three graphs, and in the Fig. 4, was the $\mathrm{SO}_{\mathrm{X}}$ added with the $\mathrm{NO}_{\mathrm{X}}$. The summer analysis shows the higher values of CR than in winter season in both metallic specimens evaluated. In all ranges, the CR was very fast and generates the higher negative effect, showing pitting corrosion with all air pollutants evaluated, in some areas of the metallic probes. In an electrical connection or connector, this electrochemical process will be a cause of an electrical resistance and in a short future can be deteriorate very fast these electrical components. This will avoid the electrical conductivity and turn off the industrial equipments and machines, which decreases the manufacturing productivity. The air pollutants were represented in the analysis by different colors: $\mathrm{H}_{2} \mathrm{~S}$ as light green, $\mathrm{SO}_{\mathrm{X}}$ with light blue, $\mathrm{NO}_{\mathrm{X}}$ as dark bluer, $\mathrm{O}_{3}$ with blue green and $\mathrm{CO}$ as yellow for the average of 2011 in all chemical agents. The analysis was in the summer and winter seasons to compare the values of the concentration levels of air pollutants evaluated. To the Fig. 2, in August of 2011, indicates the $\mathrm{H}_{2} \mathrm{~S}$ generates a maximum CR was $233 \mathrm{gr} . / \mathrm{m}^{2} \cdot$ year at $84 \%$ of $\mathrm{RH}, 41{ }^{\circ} \mathrm{C}$ of temperature and $0.035 \mathrm{ppm}$. In this season, the $\mathrm{SO}_{\mathrm{X}}$ generate a major $\mathrm{CR}$ of 177 mgr. $/ \mathrm{m}^{2}$.year, at $87 \%$ of $\mathrm{RH}, 38^{\circ} \mathrm{C}$ of temperature and $0.23 \mathrm{ppm}$. The effect of $\mathrm{NO}_{\mathrm{X}}$ in the $\mathrm{CR}$, originates the higher value of $132 \mathrm{gr} . / \mathrm{m}^{2} \cdot$ year at $83 \%$ of $\mathrm{RH}, 40{ }^{\circ} \mathrm{C}$ and $0.12 \mathrm{ppm}$. The $\mathrm{O}_{3}$ have an negative effect, generating a maximum CR of $182 \mathrm{gr} . \mathrm{m}^{2} \cdot$ year at $87 \%$ of $\mathrm{RH}, 37^{\circ} \mathrm{C}$ of temperature and $0.15 \mathrm{ppm}$ and the $\mathrm{CO}$ generates a major $\mathrm{CR}$ of $193 \mathrm{gr} . \mathrm{m}^{2} \cdot$ year at $84 \%$ of $\mathrm{RH}, 42{ }^{\circ} \mathrm{C}$ of temperature and $42 \mathrm{ppm}$.

The same process occurs in the Fig. 3, indicating the month of December 2011, where the CR presented was in major grade of deterioration of CR, than in summer. In this period of analysis, the maximum CR influenced by $\mathrm{H}_{2} \mathrm{~S}$ was $255 \mathrm{gr} . / \mathrm{m}^{2}$.year at $87 \%$ of $\mathrm{RH}$, $20{ }^{\circ} \mathrm{C}$ of temperature and $0.056 \mathrm{ppm}$. For the $\mathrm{SO}_{\mathrm{X}}$,

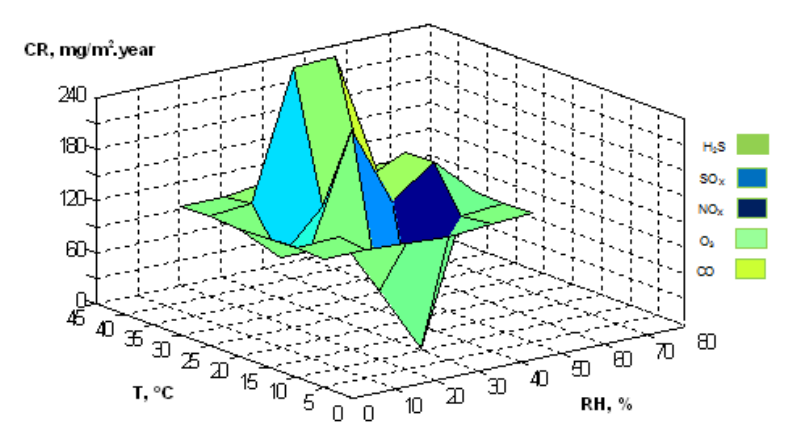

Fig. 2 Correlation of $\mathrm{CR}$ of cooper with climatic factors in summer in Mexicali (2010). AQS of air pollutants: $\mathrm{H}_{2} \mathrm{~S}$ (0.03 ppm), $\mathrm{SO}_{\mathrm{X}}(0.14 \mathrm{ppm}), \mathrm{NO}_{\mathrm{X}}(0.05 \mathrm{ppm}), \mathrm{O}_{3}(0.12$ ppm), CO (35 ppm).

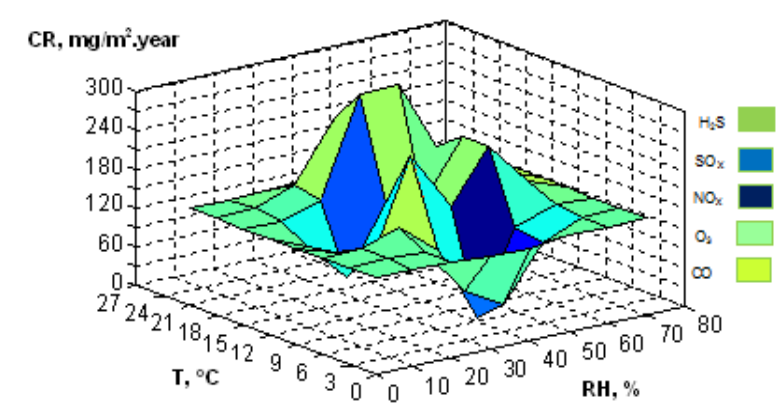

Fig. 3 Correlation of $\mathrm{CR}$ of cooper with climatic factors in winter in Mexicali (2010). AQS of air pollutants: $\mathrm{H}_{2} \mathrm{~S}(0.03$ ppm); $\mathrm{SO}_{\mathrm{X}}(0.14 \mathrm{ppm}) ; \mathrm{NO}_{\mathrm{X}}(0.05 \mathrm{ppm}) ; \mathrm{O}_{3}(0.12 \mathrm{ppm})$ and CO (35 ppm).

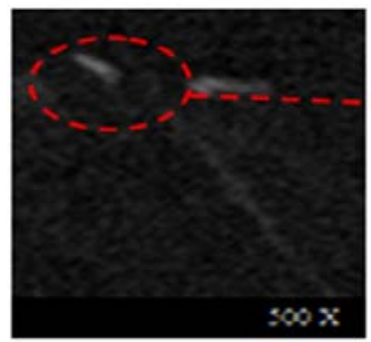

(a)

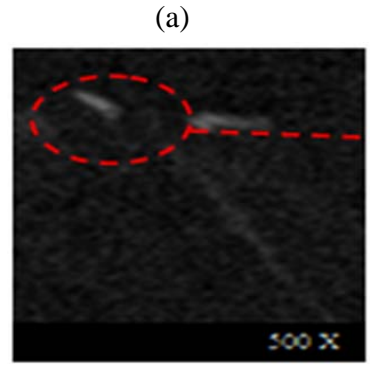

(c)

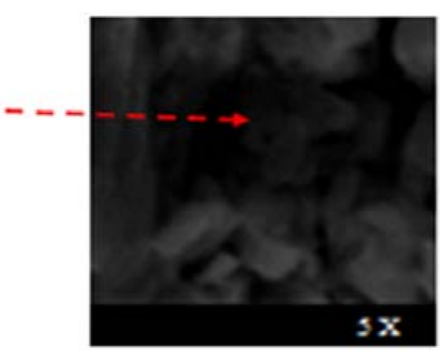

(b)
Fig. 4 Microanalysis of the deterioration of metallic surfaces of electrical connectors and connections of electromagnetic devices of PLC evaluated in indoor of a electronics industry in Mexicali (2011) in summer at (a) $500 \times$; (b) 5x; winter at (c) $500 x$ and (d) $5 \times$. 
the higher value of CR was $242 \mathrm{gr} . \mathrm{m}^{2} \cdot$ year at $82 \%$ of $\mathrm{RH}, 19{ }^{\circ} \mathrm{C}$ of temperature and $0.39 \mathrm{ppm}$. With the effect of $\mathrm{NO}_{\mathrm{X}}$ the major $\mathrm{CR}$ was $152 \mathrm{gr} . \mathrm{m}^{2} \cdot$ year at $86 \%$ of $\mathrm{RH}, 21{ }^{\circ} \mathrm{C}$ and $0.27 \mathrm{ppm}$. To the $\mathrm{O}_{3}$, the maximum CR was $239 \mathrm{gr} . \mathrm{m}^{2}$.year, at $82 \%$ of $\mathrm{RH}, 18{ }^{\circ} \mathrm{C}$ of temperature and $0.32 \mathrm{ppm}$ and to the $\mathrm{CO}$ the $\mathrm{CR}$ higher value of was $158 \mathrm{gr} . \mathrm{m}^{2} \cdot$ year at $47 \%$ of $\mathrm{RH}$, $31^{\circ} \mathrm{C}$ of temperature and $76 \mathrm{ppm}$.

\subsection{Microanalysis of Surfaces of EMD Deteriorate}

SEM technique show the deterioration of the metallic connectors and connections of electromagnetic devices used in the PLC. Fig. 4 indicates at $500 \times$ the uniform corrosion in the majorly of the surface and at $5 \times$ represents the pitting corrosion presented in a small zones of the surfaces evaluated. This damage was in the areas of electrical pathways, causing electrical failures in these types of electronic devices and systems. In the red line are showed the major deterioration.

The pitting corrosion appeared, was occurred by the variations of $\mathrm{RH}$ and temperature and the air pollution levels that exceed the AQS, showing the great major damage in winter than in summer. In both are represented at $5 \times$, pitting corrosion, but in winter in the same scale are bigger than in summer.

\section{Conclusions}

The corrosion that occurs in industrial plants, generates great economic losses, which concern people involved in these areas. Various research institutions on ways to know the origin of the different types of corrosion that can occur. One of the types of companies, where is a major concern on this topic, is the electronics industries, where occur constantly the corrosion phenomena. The electromagnetic devices suffer a variety of problems in their conduction areas in the surface films by exposition of air pollutants. When combined atmospheric agents with variations in $\mathrm{RH}$ and temperature, metallic materials used in the electronic systems as PLC, decrease their resistance corrosion of the connectors and conductive paths. This causes the formation of metallic filaments that grow between routes driving and rigid and flexible circuits between electrical connections and connectors as metallic pins or electrical unions. With increasing miniaturization of systems electronics and the explosive increase in its availability, it is estimated that the corrosion and deterioration of metal materials electronic, with incalculable consequences. The characteristics of modern electronic equipment high voltage contemplate factors, speed of operations, very small currents, miniaturization and extremely sensitive to corrosive agents. This can lead to some failures generate technical and atmospheric pollutants that attack metallic materials of electronic devices.

\section{References}

[1] P. Dillon, MTI \& DOE Launch Project Partnerships, Communications Materials Technology Institute of the Chemical Process Industries, Inc., 2000.

[2] B.G. López, Characterization of corrosion of metallic materials in the electronics industry in Mexicali, Ph.D. Thesis, B.C., 2008. (in Spanish)

[3] B.G. López, S.B. Valdez, K.R. Zlatev, P.J. Flores, B.M. Carrillo, W.M. Schorr, Corrosion of metals at indoor conditions in the electronics manufacturing industry, Anti-Corrosion Methods and Materials 54 (6) (2007) 354-359.

[4] B.G. López, S.B. Valdez, W.M. Schorr, V.H. Tiznado, H.G. Soto, Influence of climate factors on copper corrosion in electronic equipments and devices, Anti-Corrosion Methods and Materials 57 (3) (2010) 148-152.

[5] L.B. Gustavo, V.S. Benjamin, S.W. Miguel, R. Zlatev, T.V. Hugo, S.H. Gerardo, et al., AES in corrosion of electronic devices in arid in marine environments, Anti Corrosion Methods and Materials 58 (6) (2011) 331-336.

[6] A. Moncmanova, Environmental Deterioration of Materials, Universidad de Sevilla, WIT Press, Spain, 2007, pp. 108-112.

[7] L. Veleva, B. Valdez, G. López, L. Vargas, J. Flores, Atmospheric corrosion of electro-electronics metals in urban desert simulated indoor environment, Corrosion Engineering Science and Technology 43 (2) (2008) 149-155.

[8] R. Zlatev, B. Valdez, M. Stoycheva, L. Vargas, G. López, 
M. Schorr, Simpsoium 16: NACE "Corrosion and Metallurgy”, IMRC 2009, Cancun, Mexico.

[9] ISO 9223:1992, Corrosion of metals and alloys, corrosivity of atmospheres, classification.

[10] ISO 11844-2:2005, Corrosion of metals and alloys, classification of low corrosivity of indoor atmospheres, determination and estimation attack in indoor atmospheres, ISO, Geneva, 2005.
[11] ISO 11844-1:2006, Corrosion of metals and alloys, Classification of low corrosivity of indoor atmospheres, Determination and estimation of indoor corrosivity, ISO, Geneva, 2006.

[12] ASTM G91-11, Standard Practice for Monitoring Atmospheric $\mathrm{SO}_{2}$ Deposition Rate for Atmospheric Corrosivity Evaluation. 